\title{
Modulation of the Dental Pulp Stem Cell Secretory Profile by Hypoxia Induction Using Cobalt Chloride
}

\author{
Shilpa Bhandi ${ }^{1}$, Ahmed Al Kahtani ${ }^{2}$, Mohammed Mashyakhy ${ }^{1}$, Loai Alsofi ${ }^{3}{ }^{(1)}$, Prabhadevi C. Maganur ${ }^{4} \mathbb{C}^{\circ}$, \\ Satish Vishwanathaiah ${ }^{4}\left({ }^{\circ}\right.$, Luca Testarelli ${ }^{5}\left(\mathbb{0}\right.$, Andrea Del Giudice ${ }^{5}$, Deepak Mehta ${ }^{6}$, Nishant Vyas ${ }^{7}$, \\ Vikrant R. Patil ${ }^{7}$, A. Thirumal Raj ${ }^{8}(\mathbb{D})$ and Shankargouda Patil ${ }^{9, *}$
}

1 Department of Restorative Dental Sciences, College of Dentistry, Jazan University, Jazan 45142, Saudi Arabia; shilpa.bhandi@gmail.com (S.B.); dr.mashyakhy@gmail.com (M.M.)

2 Department of Restorative Dental Sciences, College of Dentistry, King Saud Universirty, Riyadh 11451, Saudi Arabia; ahkahtani@ksu.edu.sa

3 Department of Endodontics, Faculty of Dentistry, King Abdulaziz University, Jeddah 21589, Saudi Arabia; lalsofi@kau.edu.sa

4 Department of Preventive Dental Sciences, Division of Pedodontics, College of Dentistry, Jazan University, Jazan 45142, Saudi Arabia; prabhadevi.maganur@gmail.com (P.C.M.); drvsatish77@gmail.com (S.V.)

5 Department of Oral and Maxillofacial Sciences, "Sapienza" University of Rome, 00185 Rome, Italy; luca.testarelli@uniroma1.it (L.T.); andrea.delgiudice@uniroma1.it (A.D.G.)

6 Department of Preventive and Restorative Dentistry, College of Dental Medicine, University of Sharjah, Sharjah 27272, United Arab Emirates; dmehta@sharjah.ac.ae

7 Logical Life Science Private Limited, Pune 411041, India; logicalbiology84@gmail.com (N.V.); patilvikrant.r@gmail.com (V.R.P.)

check for updates

Citation: Bhandi, S.; Al Kahtani, A.; Mashyakhy, M.; Alsofi, L.; Maganur, P.C.; Vishwanathaiah, S.; Testarelli, L.; Del Giudice, A.; Mehta, D.; Vyas, N.; et al. Modulation of the Dental Pulp Stem Cell Secretory Profile by Hypoxia Induction Using Cobalt Chloride. J. Pers. Med. 2021, 11, 247. https://doi.org/10.3390/jpm11040247

Academic Editor: Sabata Martino

Received: 6 March 2021

Accepted: 23 March 2021

Published: 30 March 2021

Publisher's Note: MDPI stays neutral with regard to jurisdictional claims in published maps and institutional affiliations.

Copyright: (c) 2021 by the authors. Licensee MDPI, Basel, Switzerland. This article is an open access article distributed under the terms and conditions of the Creative Commons Attribution (CC BY) license (https:// creativecommons.org/licenses/by/ $4.0 /)$.
8 Department of Oral Pathology and Microbiology, Sri Venkateswara Dental College and Hospital, Chennai 600130, India; thirumalraj666@gmail.com

9 Department of Maxillofacial Surgery and Diagnostic Sciences, Division of Oral Pathology, College of Dentistry, Jazan University, Jazan 45142, Saudi Arabia

* Correspondence: dr.ravipatil@gmail.com

Abstract: The action of stem cells is mediated by their paracrine secretions which comprise the secretory profile. Various approaches can be used to modify the secretory profile of stem cells. Creating a hypoxic environment is one method. The present study aims to demonstrate the influence of $\mathrm{CoCl}_{2}$ in generating hypoxic conditions in a dental pulp stem cell (DPSCs) culture, and the effect of this environment on their secretory profile. DPSCs that were isolated from human permanent teeth were characterized and treated with different concentrations of $\mathrm{CoCl}_{2}$ to assess their viability by an 3-(4,5-dimethylthiazol-2-yl)-2,5-diphenyltetrazolium bromide (MTT) assay and proliferation by a cell counting kit (CCK)-8 assay. The gene expression level of hypoxia-inducible factor 1-alpha (HIF-1 $\alpha$ ) was analyzed by quantitative real time polymerase chain reaction (qRT-PCR) to demonstrate a hypoxic environment. Comparative evaluation of the growth factors and cytokines were done by cytometric bead array. Gene expression levels of transcription factors OCT4 and SOX2 were analyzed by qRT-PCR to understand the effect of $\mathrm{CoCl}_{2}$ on stemness in DPSCs. DPSCs were positive for MSC-specific markers. Doses of $\mathrm{CoCl}_{2}$, up to $20 \mu \mathrm{M}$, did not negatively affect cell viability; in low doses $(5 \mu \mathrm{M})$, it promoted cell survival. Treatment with $10 \mu \mathrm{M}$ of $\mathrm{CoCl}_{2}$ significantly augmented the genetic expression of HIF-1 $\alpha$. Cells treated with $10 \mu \mathrm{M}$ of $\mathrm{CoCl}_{2}$ showed changes in the levels of growth factors and cytokines produced. It was very evident that $\mathrm{CoCl}_{2}$ also increased the expression of OCT4 and SOX2, which is the modulation of stemness of DPSCs. A $\mathrm{CoCl}_{2}$ treatment-induced hypoxic environment modulates the secretory profile of DPSCs.

Keywords: cobalt chloride; dental pulp stem cells; hypoxia inducible factor; secretory profile; stemness

\section{Introduction}

The dental pulp forms the core of every vital tooth. It has a nutritive, formative, and reparative function. To fulfill these functions, it has a complex architecture and contains 
numerous cells and tissues such as lymphatics, neural fibres, connective tissue, blood vessels, and stem cells. Stem cells are pluripotent cells capable of giving rise to specialized cells in the body. The ones present in the dental pulp, also known as dental pulp stem cells (DPSCs), are a kind of mesenchymal stem cell (MSCs). They were first described, as well as characterized, by Gronthos et al. in 2000 and were found to be comparable to bone marrow stem cells [1]. DPSCs express stem cell markers such as KLF4, OCT4, SOX2, SSEA-3, SSEA-4, and Nanog [2,3]. They respond by separating into specialized cells if the dental pulp suffers an insult. They give rise to dentin-forming cells, i.e., odontoblasts, when they are damaged due to an external stimulus to help maintain the integrity of the pulp. DPSCs also have adipogenic, osteogenic, chondrogenic, myogenic, and neurogenic potential $[2,4,5]$. DPSCs offer the advantage of being isolated by non-invasive methods from their source such as being extracted from wisdom teeth. They can be cryopreserved and still retain their multipotent characteristics [5-7]. They have applications in regenerative endodontic therapy, bone regeneration, formation of neural tissues, healing, angiogenesis, cartilage synthesis, and immunomodulation [8]. DPSCs have also been used as carriers for the targeted delivery of the anti-cancer drug, paclitaxel, making them a potential therapeutic option that can reduce morbidity from chemotherapy [9].

The therapeutic action of stem cells is not solely a result of the replacement of dead or injured cells. After intravenous, intra-arterial, or intra-peritoneal infusion, most mesenchymal stem cells are entrapped in the lungs after $48 \mathrm{~h} \mathrm{[10].} \mathrm{Therapeutic} \mathrm{effects} \mathrm{of} \mathrm{stem} \mathrm{cells} \mathrm{are}$ seen regardless of cell migration to affected areas. This is attributed to the paracrine actions of MSCs. All living cells produce proteins within the extracellular space, which include enzymes, chemokines, cytokines, adhesion molecules, and growth factors. The collective term for these extracellular secretions is secretory profile [11,12]. MSC secretory profiles have heterogeneity in different populations and possess therapeutic potential for many diseases [11]. A DPSC secretory profile has a positive effect on the viability of cells, helps protect against cytotoxicity, and enhances the potential for repair and mineralization [13]. The secretory profile from stem cells obtained from deciduous teeth has been used for the treatment of osteoarthritis in the temporomandibular joint of a mouse model [14].

Various approaches can be used to modify the secretory profile of MSCs. These include molecular priming, hypoxic preconditioning, tissue engineering, and growth media composition [11]. Of all the mentioned approaches, hypoxia is of interest as the local oxygen concentration in the tissues where an MSCs resides is below normal $[15,16]$. The dental pulp also has a hypoxic environment in animal models $[17,18]$. In vitro studies on mesenchymal stem cells are performed at normal oxygen concentrations. In contrast, the in vivo conditions where the cells and their products find application have hypoxic conditions. It has therefore been suggested that hypoxic preconditioning should be made a standardized procedure for MSCs before clinical use [19].

Hypoxic conditions can be created either physically, i.e., using a hypoxic chamber with control of the oxygen levels, or chemically, by using chemicals in the culture media. The methods requiring physical control of oxygen levels require constant monitoring and specialized equipment making the use of chemicals such as cobalt chloride $\left(\mathrm{CoCl}_{2}\right)$ or dimethyloxalylglycine (DMOG) a more favourable choice [20]. $\mathrm{CoCl}_{2}$ has been used several times to induce and mimic hypoxic conditions, in vitro [21].

The hypoxia inducible factor (HIF) is a transcription factor with an $\alpha$ subunit $(-1 \alpha$, $-2 \alpha$ and $-3 \alpha$ ), which is oxygen controlled, and a $\beta$ subunit [22]. The subunit responsible for optimizing respiration under hypoxic conditions is HIF- $1 \alpha$. It is constantly synthesized and degraded in normoxic conditions but stabilizes in a hypoxic environment. $\mathrm{CoCl}_{2}$ stabilizes HIF- $1 \alpha$ under normoxic conditions, inducing chemical hypoxia which lasts several hours [21]. This has utility in studying stem cell markers and osteogenic differentiation in human DPSCs (hDPSCs) and periodontal cells [23-25]. However, the effect of these hypoxic conditions on the secretory profile has not been evaluated in detail.

The objective of this study was to evaluate the influence of $\mathrm{CoCl}_{2}$ induced hypoxia on the secretory profile of human dental pulp stem cells as well as on the stemness of the same. 
We specifically aimed to study the effect of this condition on the cytokines and growth factors in the secretions of hDPSCs and the effects and expression levels of OCT4 and SOX2, the stemness transcription factors. The potential clinical relevance for the present study was to assess if inducing a hypoxic state could maximize the regenerative potential of hDPSCs. Augmented stemness through hypoxia could aid in prolonging/potentiating the hDPSCs regenerative potential. Based on the results of the present study, future studies could use hypoxia as an optimizing condition for eliciting augmented proliferative and differentiative properties.

\section{Materials and Methods}

\subsection{Sample Collection}

Samples were obtained from extracted human premolar teeth from healthy subjects aged 18-25 after obtaining their consent. The extractions were carried out for orthodontic treatment. 5 premolar teeth were collected from patients with good oral hygiene. The pulp was isolated under sterile conditions and transferred to the laboratory for further processing.

\subsection{Isolation and Culture of DPSCs}

DPSCs were isolated using the long-term explant culture technique which has been described in detail in another paper [26]. Small fragments of the pulp tissue, measuring $\sim 1 \mathrm{~mm}$, were placed in culture flasks and covered completely in fetal bovine serum (FBS) and incubated. The explant was sustained in a Dulbecco's Modified Eagle's Medium (DMEM) of $20 \%$ fetal bovine serum and supplementary antibiotic-antimycotic solution. It was maintained in a humid environment of $5 \% \mathrm{CO}_{2}$ at a temperature of $37^{\circ} \mathrm{C}$. The culture medium was renewed every $2-3$ days. Cellular outgrowth was monitored regularly with an inverted phase-contrast microscope. Cells that were outgrown with a 70-80\% confluence were removed from the flasks by trypsinization and transferred to another flask. The primary explant culture was maintained. DPSCs obtained at passage 4 were used characterized and studied.

\subsection{Characterization Using Flow Cytometry}

Confluent DPSCs harvested from the flask by trypsinization were washed with phosphate-buffered saline. After incubating in the dark at room temperature for thirty minutes with human leukocyte antigen-DR isotype (HLA-DR), CD73, CD90, and CD105 antibodies, phosphate-buffered saline was used to wash the cells. They were then analyzed on a flow cytometer. No less than ten thousand events were acquired per sample. The extent of positive staining was taken as a percentage to compare to the controls.

\subsection{3-(4,5-Dimethylthiazol-2-yl)-2,5-Diphenyltetrazolium Bromide (MTT) Assay}

This assay checked the viability of DPSCs treated with the different concentrations of $\mathrm{CoCl}_{2}$. A control group without treatment, and cells treated with concentrations of 5, 10, 20 , and $40 \mu \mathrm{M}$ were used. After being seeded into 96 well plates, the cells were incubated with culture media and $\mathrm{CoCl}_{2}$ for $48 \mathrm{~h}$. Following this, the MTT solution of a $0.5 \mathrm{mg} / \mathrm{mL}$ concentration was placed in individual wells, and these were incubated for $4 \mathrm{~h}$ at $37^{\circ} \mathrm{C}$. Subsequently, the media was replaced with $100 \mu \mathrm{L}$ of dimethyl sulfoxide in every well. A spectrophotometry plate reader was used to evaluate the absorbance seen at $570 \mathrm{~nm}$.

\subsection{Cell Proliferation Assay CCK-8 (Cell Counting Kit 8 Assay)}

This assay was done, at 1 to 10 days, in treatments with $\mathrm{CoCl}_{2}(10 \mu \mathrm{M})$ and in the control group with no treatment. CCK- 8 is a colorimetric reaction-based assay that yields an orange formazan dye to an extent proportional with the cell number. The proliferation rate of DPSCs was calculated by evaluating the absorbance at $450 \mathrm{~nm}$ on a spectrophotometer. 


\subsection{Quantitative Real-Time PCR for Analysis of Gene Expression}

For this test, a complementary DNA (cDNA) synthesis kit was used to reverse transcribe $1 \mu \mathrm{g}$ of total RNA, as per manufacturer guidelines. Quantitative analysis of the gene of interest (HIF- $1 \alpha$ ) was done using the SYBR Green PCR master mix, using a qRT-PCR machine, in treated $\left(10 \mu \mathrm{M} \mathrm{CoCl}_{2}\right)$ and untreated groups. Normalization of the expressions of target genes to $\mathrm{B}$-actin was done by using the $\Delta \Delta \mathrm{Ct}$ technique. The quantification of data was done by using the $2^{-\Delta \Delta \mathrm{Ct}}$ technique, and indicated as a normalized relative expression of the gene compared to the average of the $\beta$-actin gene $C T$ value. The utilized primer sequences are mentioned in Table 1.

Table 1. Primer Sequences used for PCR.

\begin{tabular}{|c|c|c|}
\hline Gene & Forward Primer & Reverse Primer \\
\hline $\mathrm{HIF}-1 \alpha$ & 5'-CTT CTG AGC TCT GAT GAG GC-3' & $5^{\prime}$-GAA AGC ACC ATC AGG AAG CC-3' \\
\hline OCT4 & 5'-TTT TGG TAC CCC AGG CTA TG-3' & 5'-GCA GGC ACC TCA GTT TGA AT-3' \\
\hline SOX2 & 5'-GAG CTT TGC AGG AAG TTT GC-3' & $5^{\prime}$-GCA AGA AGC CTC TCC TTG AA-3' \\
\hline ACTB & 5'-AGA GCT ACG AGC TGC CTG AC-3' & 5'-AGC ACT GTG TTG GCG TAC AG-3' \\
\hline
\end{tabular}

\subsection{Cytometric Bead Array for the Detection of Cytokines and Growth Factors}

For evaluating the levels of the cytokines and growth factors in the conditioned media for DPSCs, with and without treatment using $\mathrm{CoCl}_{2}$, a cytometric bead array was done. A LEGENDplex ${ }^{\mathrm{TM}}$ Human Growth Factor Panel (13-plex) (Biolegend; 740180 San Diego, CA, USA) (VEGF, Ang-2, EGF, EPO, FGF-basic, PDGF-AA, PDGF-BB, G-CSF, GM-CSF, HGF, M-CSF, SCF, TGF- $\alpha$ ) was used for the detection of the growth factors. A LEGENDplex $^{\mathrm{TM}}$ Human Essential Immune Response Panel (13-plex) (Biolegend; 740929) (IL 4, IL 2, IL 1 $\beta$, IL 17A, IL 6, IL 10, IL 12p70, TNF $\alpha$, CXCL8, CXCL10, CCL2, IFN $\gamma$, TGF $\beta 1$ ) was used for the detection of the cytokines. The experimental protocol was performed as per the manufacturer's guidelines. Briefly, $25 \mu \mathrm{L}$ of the conditioned media was incubated with the microbeads, and detection antibodies were subsequently introduced. The samples were then evaluated using a flow cytometer and analysis was performed by using LEGENDplex ${ }^{\mathrm{TM}}$ Data Analysis Software.

\subsection{Statistical Analysis}

All the samples were experimented in triplicate. All the experimental protocols were performed three times. Means and standard deviations of all the experimental values for each sample were used to represent the data for five individual samples. The statistical significances between the experimental groups were determined by a paired $t$-test (twotailed) and $p$-values were calculated using the GraphPad Prism 8 software (GraphPad Software, La Jolla, CA, USA). A $p$-value of less than 0.05 was measured as significant (Significance Levels: ns not significant, ${ }^{*} p<0.05$, and ${ }^{* *} p<0.01$ ).

\section{Results}

\subsection{DPSC Characterization}

Morphological evaluation, done using the inverted phase contrast microscope, showed an elongated spindle-shaped morphology of the isolated cells (Figure 1A). The cells displayed mesenchymal stem cell-specific markers CD73, CD90, and CD105. The MHC Class II cell surface receptor was absent in the cultured cells (Figure 1B). Thus, the DPSCs had an MSC-like morphology and stem cell surface markers. 


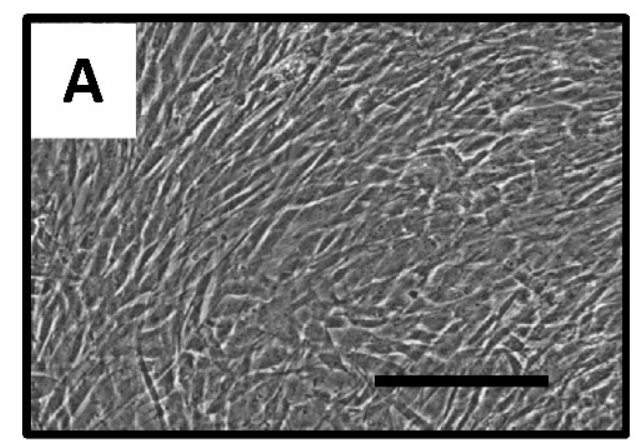

DPSCs - Passage 4

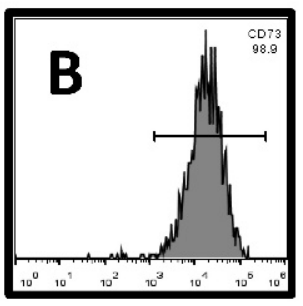

CD73 (98.9\%)

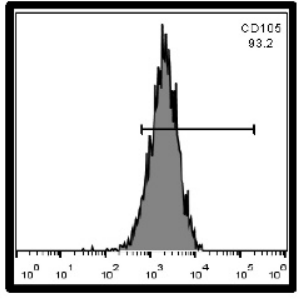

CD105 (93.2\%)

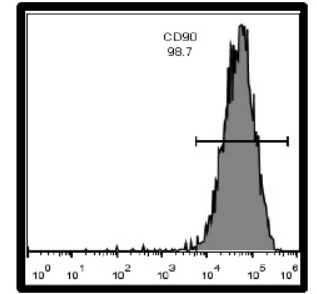

CD90 (98.7\%)

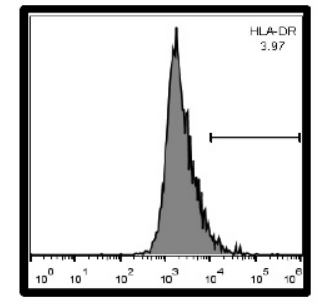

HLA-DR (3.97\%)
C MTT assay - 48 hours

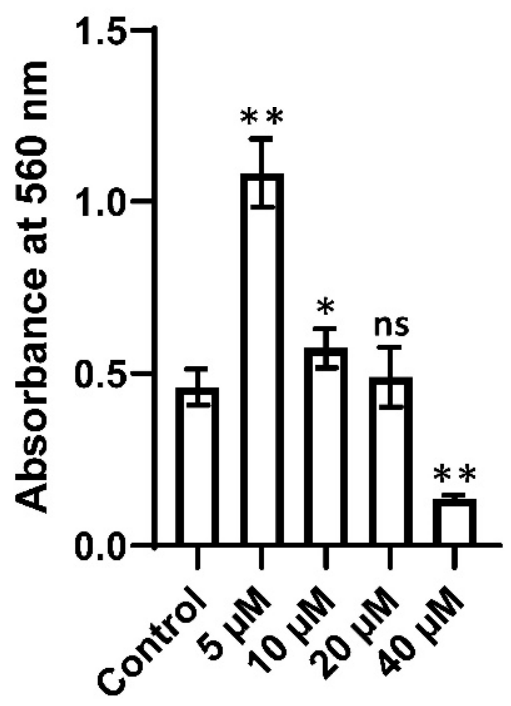

Figure 1. (A): elongated spindle-shaped morphology of the isolated cells; (B): MHC II class representation; (C): cell viability at high concentration of $\mathrm{CoCl}_{2}$. ns not significant, ${ }^{*} p<0.05$, and ** $p<0.01$.

\subsection{Effect of $\mathrm{CoCl}_{2}$ on Proliferation and Viability}

After $48 \mathrm{~h}$, no difference in cellular metabolism was observed by the MTT assay. However, a low dose of $5 \mu \mathrm{M}$ showed a significant increase in cell metabolism, which was the highest of all the concentrations used. The cell viability was lowest at a high concentration of $\mathrm{CoCl}_{2}(40 \mu \mathrm{M})$ after $48 \mathrm{~h}$ (Figure $\left.1 \mathrm{C}\right)$ (Table 2). Cell viability was significantly unaffected by the $\mathrm{CoCl}_{2}$ treatment, for concentrations of 10 and $20 \mu \mathrm{M}$.

Table 2. Effect of $\mathrm{CoCl}_{2}$ on viability.

\begin{tabular}{cccccc}
\hline $\mathbf{C o C l}_{\mathbf{2}}$ Treatment & Control & $\mathbf{5} \boldsymbol{\mu M}$ & $\mathbf{1 0} \boldsymbol{\mu M}$ & $\mathbf{2 0} \boldsymbol{\mu M}$ & $\mathbf{4 0} \boldsymbol{\mu M}$ \\
\hline Absorbance at $560 \mathrm{~nm}$ & $0.46 \pm 0.052$ & $1.082 \pm 0.098$ & $0.57 \pm 0.056$ & $0.49 \pm 0.086$ & $0.13 \pm 0.010$ \\
\hline$p$ value (vs. Control) & & $<0.0001$ & 0.0116 & 0.5352 & $<0.0001$ \\
\hline
\end{tabular}

Cell proliferation measured by the CCK-8 Assay showed a higher absorbance of cells treated with $\mathrm{CoCL}_{2}(10 \mu \mathrm{M})$ at all times. However, the results were significant only on day 9. (Figure 2A) (Table 3). Thus, $\mathrm{CoCL}_{2}$ had a positive effect on cell viability at low concentrations and proliferation was also higher upon treatment. 

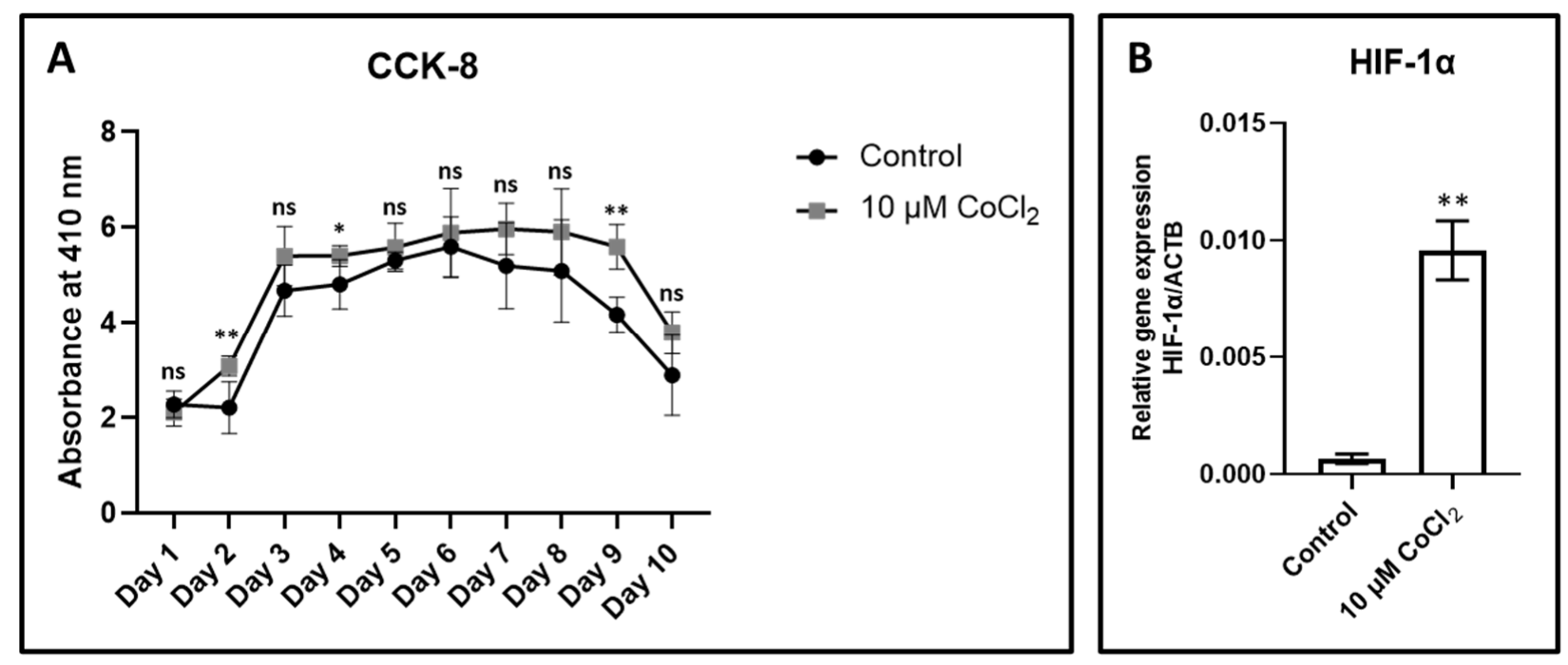

Figure 2. (A): Chronological evaluation of absorbability; (B): PCR results. ns not significant, ${ }^{*} p<0.05$, and ${ }^{* *} p<0.01$.

Table 3. Effect of $\mathrm{CoCl}_{2}$ on proliferation.

\begin{tabular}{cccc}
\hline CCK-8 Assay & Control & $\mathbf{1 0} \boldsymbol{\mu} \mathbf{M ~} \mathbf{C o C l}_{\mathbf{2}}$ & $\boldsymbol{p}$ Value (vs. Control) \\
\hline Day 1 & $2.27 \pm 0.27$ & $2.10 \pm 0.28$ & 0.3709 \\
Day 2 & $2.21 \pm 0.54$ & $3.08 \pm 0.21$ & 0.0096 \\
Day 3 & $4.67 \pm 0.53$ & $5.4 \pm 0.62$ & 0.0853 \\
Day 4 & $4.81 \pm 0.52$ & $5.41 \pm 0.21$ & 0.0449 \\
Day 5 & $5.31 \pm 0.18$ & $5.58 \pm 0.50$ & 0.2820 \\
Day 6 & $5.59 \pm 0.63$ & $5.88 \pm 0.92$ & 0.5721 \\
Day 7 & $5.19 \pm 0.90$ & $5.97 \pm 0.53$ & 0.1391 \\
Day 8 & $5.08 \pm 1.07$ & $5.91 \pm 0.90$ & 0.2270 \\
Day 9 & $4.16 \pm 0.36$ & $5.59 \pm 0.46$ & 0.0007 \\
Day 10 & $2.89 \pm 0.84$ & $3.78 \pm 0.44$ & 0.0685 \\
\hline
\end{tabular}

\subsection{Expression of Hypoxia-Inducing Gene HIF-1 $\alpha$}

A significant upregulation of $\mathrm{HIF}-1 \alpha$, after treatment with $10 \mu \mathrm{M} \mathrm{CoCl}_{2}$ compared to an untreated group, was observed in the quantitative real time PCR results (Figure 2B) (Table 4).

Table 4. Effect of $\mathrm{CoCl}_{2}$ on HIF $-1 \alpha$ expression.

\begin{tabular}{cccc}
\hline Relative Gene Expression/ACTB & Control & $\mathbf{1 0} \boldsymbol{\mu \mathbf { M ~ C o C l }}$ & $p$ Value (vs. Control) \\
\hline HIF- $1 \alpha$ & $0.00065 \pm 0.000019$ & $0.0095 \pm 0.0012$ & $<0.0001$ \\
\hline
\end{tabular}

\subsection{Modulation of the Secretory Profile of DPSCs in Terms of Growth Factors and Cytokines}

A comparative analysis of the cytokines and growth factors in the conditioned-media from DPSCs and $\mathrm{CoCl}_{2}$-treated DPSCs showed that the growth factors, especially those associated with angiogenesis were higher in the secretory profile of $\mathrm{CoCl}_{2}$-treated DPSCs. These molecules include Ang-2, EGF, bFGF, SCF, and VEGF (Figure 3A) (Table 5). Another observation was higher levels of the anti-inflammatory cytokines CCL2, CXCL10, and TGF- $\beta 1$, and reduced secretion of interferon gamma and interleukins 4,6 , and 10 by DPSCs treated with $\mathrm{CoCl}_{2}$ (Figure 3B) (Table 6). 

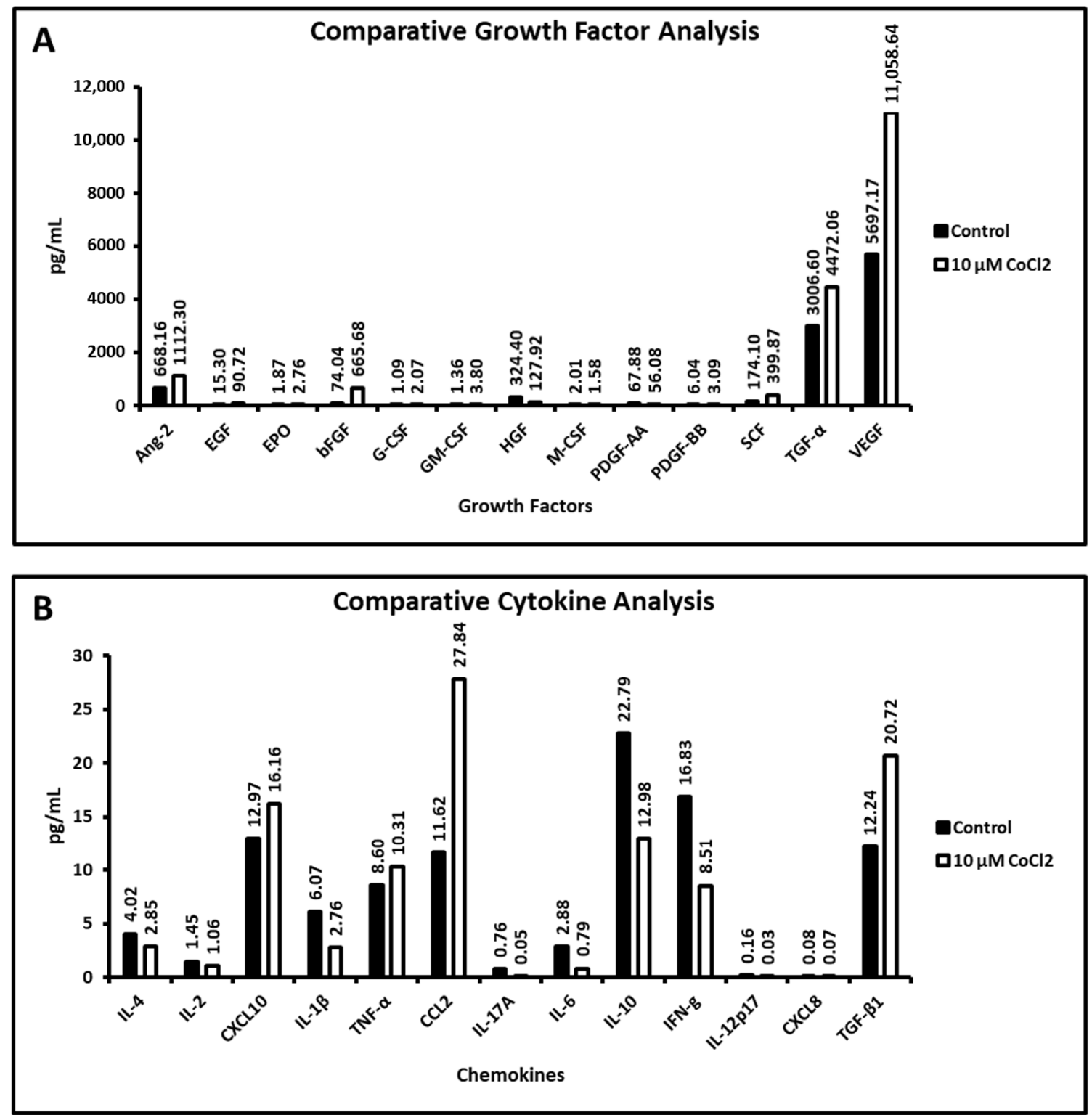

Figure 3. (A): growth factor distribution; (B): Inflammatory cytokines distribution.

Table 5. Effect of $\mathrm{CoCl}_{2}$ on growth factor secretion by DPSCs.

\begin{tabular}{ccc}
\hline Growth Factors & Control & $\mathbf{1 0} \boldsymbol{\mu} \mathbf{M ~ C o C l}_{\mathbf{2}}$ \\
\hline Ang-2 & 668.16 & 1112.30 \\
EGF & 15.29 & 90.72 \\
EPO & 1.87 & 2.76 \\
bFGF & 74.04 & 665.68 \\
G-CSF & 1.09 & 2.07 \\
GM-CSF & 1.36 & 3.80 \\
HGF & 324.40 & 127.92 \\
M-CSF & 2.01 & 1.58 \\
PDGF-AA & 67.88 & 56.08 \\
PDGF-BB & 6.04 & 3.09 \\
SCF & 174.10 & 399.87 \\
TGF- $\alpha$ & 3006.60 & 4472.06 \\
VEGF & 5697.17 & $11,058.64$ \\
\hline
\end{tabular}


Table 6. Effect of $\mathrm{CoCl}_{2}$ on cytokine secretion by DPSCs.

\begin{tabular}{ccc}
\hline Cytokines & Control & $\mathbf{1 0} \boldsymbol{\mu} \mathbf{M} \mathbf{C o C l}_{\mathbf{2}}$ \\
\hline IL-4 & 4.02 & 2.85 \\
IL-2 & 1.45 & 1.06 \\
CXCL10 & 12.97 & 16.16 \\
IL-1 $\beta$ & 6.07 & 2.76 \\
TNF- $\alpha$ & 8.59 & 10.30 \\
CCL2 & 11.62 & 27.84 \\
IL-17A & 0.76 & 0.05 \\
IL-6 & 2.85 & 0.79 \\
IL-10 & 22.79 & 12.97 \\
IFN-g & 16.83 & 8.51 \\
IL-12p17 & 0.16 & 0.03 \\
CXCL8 & 0.08 & 0.07 \\
TGF- $\beta 1$ & 12.23 & 20.72 \\
\hline
\end{tabular}

\subsection{Effect of CoCl2 Induced Hypoxia on Gene Expression of OCT4 and SOX2}

The $\mathrm{CoCl}_{2}$ treated and untreated DPSCs were studied for the gene expression of stemness transcription factors OCT4 and SOX2. $10 \mu \mathrm{M}$ of $\mathrm{CoCl}_{2}$ treated DPSCs showed elevated levels of OCT4 and SOX2 expression levels, with respect to the mRNA when compared with untreated cells (Figure 4A,B) (Table 7).
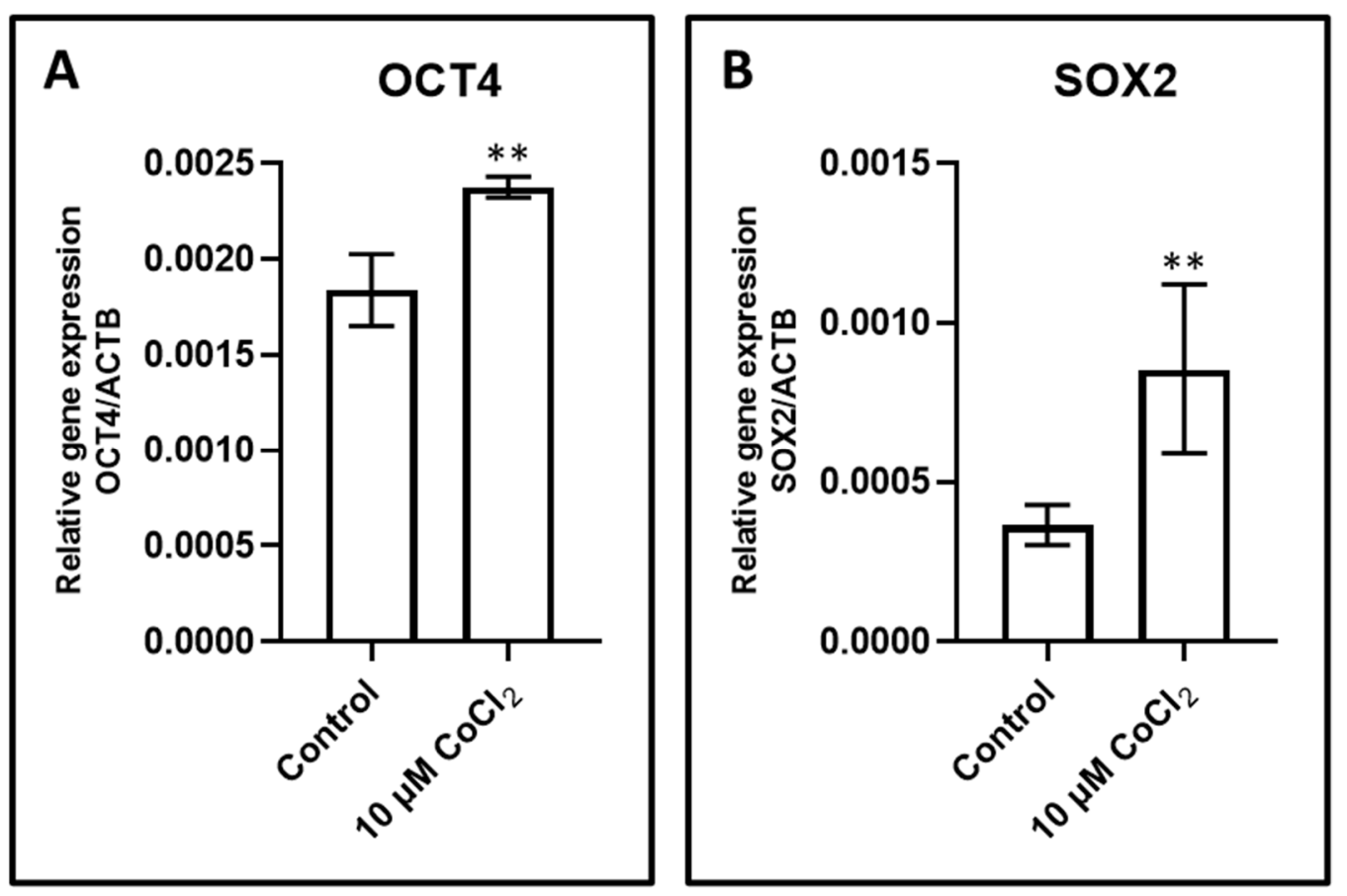

Figure 4. (A): OCT4 levels; (B): SOX2 levels. ns not significant, ${ }^{* *} p<0.01$.

Table 7. Effect of $\mathrm{CoCl}_{2}$ on stemness related genes OCT4 and SOX2 expression in DPSCs.

\begin{tabular}{cccc}
\hline Relative Gene Expression/ACTB & Control & $\mathbf{1 0} \boldsymbol{\mu} \mathbf{M ~ C o C l}$ & $p$ Value (vs. Control) \\
\hline OCT4 & $0.0018 \pm 0.00019$ & $0.0023 \pm 0.000054$ & 0.0003 \\
SOX2 & $0.00036 \pm 0.000062$ & $0.00084 \pm 0.00026$ & 0.0039 \\
\hline
\end{tabular}




\section{Discussion}

In this study, we aimed to demonstrate that hypoxic conditions can modify the secretory profile of DPSCs. As observed in previous studies, DPSCs have characteristics similar to mesenchymal stem cells which were also seen in this study [1,4]. These similarities betweeen the DPSCs and MSCs are maintained in vivo as well [27]. The lack of MHC receptors indicates that these cells might have use as allogenic sources in vivo without inducing an immune response. Hypoxic conditions are known to affect mesenchymal stem cells. They have demonstrated positive effects on cell proliferation and surface markers for MSCs [16,28,29]. Similar results have been observed in DPSCs as well [23,24]. In DPSCs, hypoxic conditions were able to enhance the angiogenic activity and decreased the osteogenic differentiation of these cells $[23,30,31]$.

$\mathrm{CoCl}_{2}$ is a mimetic hypoxia agent, like many others. It has been used to induce chemical hypoxia for studying stem cells. It has demonstrated responses similar to those produced by cells subjected to hypoxia [21,32]. The mechanism of action that $\mathrm{CoCl}_{2}$ uses in producing a hypoxic environment is attributed to the substitution of iron by cobalt ions in prolyl hydroxylases (PHDs). These enzymes are responsible for the degradation of the hypoxia induced factor in normal oxygen concentrations. $\mathrm{CoCl}_{2}$ thus stabilizes the HIF expression and creates a response similar to a hypoxic condition. Various concentrations of $\mathrm{CoCl}_{2}$ have been used to study stem cells. High concentrations of $100 \mu \mathrm{M}$ have been shown to induce cell death in dental pulp stem cells, while the same concentration does not affect periodontal cells $[23,25]$. Even in MSCs, the effect of $\mathrm{CoCl}_{2}$ is debated with conflicting results in the studies $[20,33]$. These conflicting results may be obtained due to the varying influence of $\mathrm{CoCl}_{2}$ depending on the cell type and the concentration of the solution used. Further research in this regard can help identify the ideal conditions for studying different cell types.

HIF 1 regulates the haemostatic response to hypoxia. An increase in the hypoxia inducible factor is the foremost response in cells under hypoxic stress [34]. It acts by reprogramming the glycolytic metabolism and inducing genes encoding phosphofructokinase, pyruvate kinase, and hexokinase, and glucose transporters 1 and 3 [35]. Another effect of HIF is the upregulation of gene encoding proteins involved in angiogenesis and erythropoiesis [36]. Although $\mathrm{CoCl}_{2}$ is known to induce hypoxia-like conditions via stabilization of HIF, there are other factors such as the physical presence of oxygen ions, which make it difficult to attribute the extent of the observed effects to hypoxia.

Regarding stem cells, hypoxia has been proven to be essential for the upkeep of stem cell properties, that is their multipotency, self-renewal, and survival [37]. However, the influence of hypoxia on the secretory profile of stem cells of the dental pulp, needs further research. This study shows that hypoxic conditions do affect the secretory profile of dental pulp stem cells. There was an increase in angiogenic cytokines which can be expected with an upregulation of HIF $1 \alpha$. Growth factors such as EPO, Ang -2, bFGF, SCF, TGF $\alpha$, and VEGF were increased (Figure 3A). This indicates an enhanced anabolic potential in the treated cells compared to controls. The hypoxia primed cells will probably be more effective and efficient than untreated controls in affecting therapeutic changes. The cytokine secretion was also modulated by hypoxia. The levels of certain chemokines CXCL10 and CCL2 were higher whereas interleukins were reduced. This indicates that the hypoxic condition promotes cell signaling and communication, but at the same time reduces pro-inflammatory activity. The overall effect of the chemical hypoxia appears to be an increase in synthetic activity and reduced inflammation in the DPSC secretory profile.

The effect of hypoxia on the secretory profile of stem cells has been studied before. In a 3-D culture system, DPSCs under hypoxia showed an elevated secretion of IL-6 [38]. In another study on a mesenchymal stem cell sheet, secretions of VEGF, bFGF and collagen I and III were enhanced under hypoxic conditions [39]. Along with an enhanced proliferation, the chemokine receptor (CXCR4) has also been demonstrated to be elevated on DPSCs under hypoxia [40]. The increased secretion of these pro-angiogenic and anti-inflammatory 
factors is what could provide a potential therapeutic application to DPSCs. They have been used in the form of nanofibrous microspheres to aid in the regeneration of the pulp [41].

OCT4 and SOX2 are the transcription factors which define the stemness of the stem cells. Both of these transcription factors control various epigenetic processes, molecular regulatory pathways, and even the proliferation in stem cells. In the current study the hypoxia induced by $\mathrm{CoCl}_{2}$ increased the gene expression of both OCT4 and SOX2 (Figure 4A,B), it is a very good indication for potential new directions of research where the stemness and the quality of DPSCs can be increased by chemically induced hypoxia.

To be used as therapeutic agents, stem cells must be easily harvested and provide desired benefits, with minimal adverse effects. Dental stem cells obtained from various sources are helpful in this regard. The secretory profile of stem cells plays a major role in their action. Various approaches in modifying the secretory profile need to be researched to provide the appropriate molecular therapy for a disease. Inducing hypoxia, as in the present study, has been shown to augment DPMSC regenerative properties, including osteogenic and angiogenic potential, as elicited by Maslowska et al. [42] and Dissanayaka et al. [43]. Similar studies on various molecules that bring about the modification will help to better understand the mechanism and develop protocols for future medicine. However, this study should be further expanded to examine the effect of hypoxia induction on the differentiation of DPSCs in multiple lineages, clonogenic aptitude, and cellular senescence. Moreover, the paracrine effect of DPSCs primed with a hypoxic condition need to be assessed for their immunomodulatory and regenerative potential in terms of allogeneic transplantation and wound healing ability. Furthermore, synergistic effects of hypoxia, along with some pharmaceutical conditionings, need to be studied to fill the lacunae in empowerment of DPSCs for therapeutic use. Finally, a high throughput and sophisticated experimentation should be utilized to excavate the maximum clinical efficacy of DPSCs.

\section{Conclusions}

This study demonstrates that $\mathrm{CoCl}_{2}$ can induce a hypoxia-like environment for DPSCs by stabilization of the HIF $1 \alpha$. The hypoxic environment modified the secretory profile of the DPSCs by increasing the secretion of synthetic factors and reduced the secretion of inflammatory mediators. Moreover, the stemness-related transcription factors were also found to be upregulated by $\mathrm{CoCl}_{2}$. This demonstrates an increased potential for therapeutic purposes in hypoxia primed cells over untreated cells.

Author Contributions: Conceptualization, S.B., A.A.K.; methodology, M.M., L.A.; software, P.C.M., S.V.; validation, L.T., A.D.G.; formal analysis, D.M., N.V.; investigation, A.T.R., S.P.; re-sources, S.B., A.A.K.; data curation, M.M., L.A.; writing-original draft preparation, S.B., A.A.K., M.M., L.A., P.C.M., S.V.; writing—review and editing, L.T., A.D.G., D.M., N.V., A.T.R., S.P.; vis-ualization, P.C.M., S.V.; supervision, L.T., A.T.R., S.P.; project administration, S.B., A.A.K.; funding acquisition, V.R.P. All authors have read and agreed to the published version of the manuscript.

Funding: This research received no external funding.

Institutional Review Board Statement: The study was conducted according to the guidelines of the Declaration of Helsinki, and approved by the Institutional Review Board of College of Dentistry, Jazan University (Reference number: CODJU-19675, Approval date- 21-05-2020).

Informed Consent Statement: Informed consent was obtained from all subjects involved in the study.

Data Availability Statement: The data presented in this study are available on request from the corresponding author.

Conflicts of Interest: The authors declare no conflict of interest. 


\section{References}

1. Gronthos, S.; Mankani, M.; Brahim, J.; Robey, P.G.; Shi, S. Postnatal human dental pulp stem cells (DPSCs) in vitro and in vivo. Proc. Natl. Acad. Sci. USA 2000, 97, 13625-13630. [CrossRef] [PubMed]

2. Kerkis, I.; Kerkis, A.; Dozortsev, D.; Stukart-Parsons, G.C.; Gomes Massironi, S.M.; Pereira, L.V.; Caplan, A.I.; Cerruti, H.F. Isolation and characterization of a population of immature dental pulp stem cells expressing OCT-4 and other embryonic stem cell markers. Cells Tissues Organs 2007, 184, 105-116. [CrossRef] [PubMed]

3. Ahmed, N.E.M.B.; Murakami, M.; Kaneko, S.; Nakashima, M. The effects of hypoxia on the stemness properties of human dental pulp stem cells (DPSCs). Sci. Rep. 2016, 6, 35476. [CrossRef] [PubMed]

4. Gronthos, S.; Brahim, J.; Li, W.; Fisher, L.W.; Cherman, N.; Boyde, A.; Denbesten, P.; Robey, P.G.; Shi, S. Stem Cell Properties of human dental pulp stem cells. J. Dent. Res. 2002, 81, 531-535. [CrossRef] [PubMed]

5. Zhang, W.; Walboomers, X.F.; Shi, S.; Fan, M.; Jansen, J.A. Multilineage differentiation potential of stem cells derived from human dental pulp after cryopreservation. Tissue Eng. 2006, 12, 2813-2823. [CrossRef] [PubMed]

6. Lee, S.Y.; Huang, G.W.; Shiung, J.N.; Huang, Y.H.; Jeng, J.H.; Kuo, T.F.; Yang, J.C.; Yang, W.C.V. Magnetic cryopreservation for dental pulp stem cells. Cells Tissues Organs 2012, 196, 23-33. [CrossRef] [PubMed]

7. Kumar, A.; Bhattacharyya, S.; Rattan, V. Effect of uncontrolled freezing on biological characteristics of human dental pulp stem cells. Cell Tissue Bank. 2015, 16, 513-522. [CrossRef]

8. Yang, X.; Li, L.; Xiao, L.; Zhang, D. Recycle the dental fairy's package: Overview of dental pulp stem cells. Stem Cell Res. Ther. 2018, 9, 347. [CrossRef]

9. Salehi, H.; Al-Arag, S.; Middendorp, E.; Gergely, C.; Cuisinier, F.; Orti, V. Dental pulp stem cells used to deliver the anticancer drug paclitaxel. Stem Cell Res. Ther. 2018, 9, 103. [CrossRef]

10. Gao, J.; Dennis, J.E.; Muzic, R.F.; Lundberg, M.; Caplan, A.I. The dynamic in vivo distribution of bone marrow-derived MSC after infusion.pdf. Cells Tissue Organs 2001, 7080, 12-20. [CrossRef]

11. Cunningham, C.J.; Redondo-Castro, E.; Allan, S.M. The therapeutic potential of the mesenchymal stem cell secretome in ischaemic stroke. J. Cereb. Blood Flow Metab. 2018, 38, 1276-1292. [CrossRef] [PubMed]

12. Vizoso, F.J.; Eiro, N.; Cid, S.; Schneider, J.; Perez-Fernandez, R. Mesenchymal stem cell secretome: Toward cell-free therapeutic strategies in regenerative medicine. Int. J. Mol. Sci. 2017, 18, 1852. [CrossRef] [PubMed]

13. Paschalidis, T.; Bakopoulou, A.; Papa, P.; Leyhausen, G.; Geurtsen, W.; Koidis, P. Dental pulp stem cells' secretome enhances pulp repair processes and compensates TEGDMA-induced cytotoxicity. Dent. Mater. 2014, 30, e405-e418. [CrossRef] [PubMed]

14. Ogasawara, N.; Kano, F.; Hashimoto, N.; Mori, H.; Liu, Y.; Xia, L.; Sakamaki, T.; Hibi, H.; Iwamoto, T.; Tanaka, E.; et al. Factors secreted from dental pulp stem cells show multifaceted benefits for treating experimental temporomandibular joint osteoarthritis. Osteoarthr. Cartil. 2020, 28, 831-841. [CrossRef]

15. Spencer, J.A.; Ferraro, F.; Roussakis, E.; Klein, A.; Runnels, J.M.; Zaher, W.; Mortensen, L.J.; Alt, C.; Yusuf, R.; Côté, D.; et al. Direct measurement of local oxygen concentration in the bone marrow of live animals. Nature 2014, 508, 269-273. [CrossRef]

16. Lee, J.H.; Yoon, Y.M.; Lee, S.H. Hypoxic preconditioning promotes the bioactivities of mesenchymal stem cells via the HIF-1 $\alpha$ GRP78-Akt axis. Int. J. Mol. Sci. 2017, 18, 1320. [CrossRef] [PubMed]

17. Yu, C.Y.; Boyd, N.M.; Cringle, S.J.; Alder, V.A.; Yu, D.Y. Oxygen distribution and consumption in rat lower incisor pulp. Arch. Oral Boil. 2002, 47, 529-536. [CrossRef]

18. Kozam, G. Oxygen Tension of Rabbit Incisor Pulp. J. Dent. Res. 1697, 46, 352-358. [CrossRef]

19. Huang, Y.C.; Parolini, O.; Deng, L.; Yu, B.S. Should hypoxia preconditioning become the standardized procedure for bone marrow MSCs preparation for clinical use? Stem Cells 2016, 34, 1992-1993. [CrossRef]

20. Zeng, H.L.; Zhong, Q.; Qin, Y.L.; Bu, Q.Q.; Han, X.A.; Jia, H.T.; Liu, H.W. Hypoxia-mimetic agents inhibit proliferation and alter the morphology of human umbilical cord-derived mesenchymal stem cells. BMC Cell Biol. 2011, 12, 1-10. [CrossRef] [PubMed]

21. Muñoz-Sánchez, J.; Chánez-Cárdenas, M.E. The use of cobalt chloride as a chemical hypoxia model. J. Appl. Toxicol. 2019, 39, 556-570. [CrossRef] [PubMed]

22. Semenza, G.L. Life with oxygen. Science 2007, 318, 62-64. [CrossRef] [PubMed]

23. Laksana, K.; Sooampon, S.; Pavasant, P.; Sriarj, W. Cobalt Chloride Enhances the Stemness of Human Dental Pulp Cells. J. Endod. 2017, 43, 760-765. [CrossRef]

24. Chen, Y.; Zhao, Q.; Yang, X.; Yu, X.; Yu, D.; Zhao, W. Effects of cobalt chloride on the stem cell marker expression and osteogenic differentiation of stem cells from human exfoliated deciduous teeth. Cell Stress Chaperones 2019, 24, 527-538. [CrossRef] [PubMed]

25. Osathanon, T.; Vivatbutsiri, P.; Sukarawan, W.; Sriarj, W.; Pavasant, P.; Sooampon, S. Cobalt chloride supplementation induces stem-cell marker expression and inhibits osteoblastic differentiation in human periodontal ligament cells. Arch. Oral Biol. 2015, 60, 29-36. [CrossRef]

26. Patil, V.R.; Kharat, A.H.; Kulkarni, D.G.; Kheur, S.M.; Bhonde, R.R. Long term explant culture for harvesting homogeneous population of human dental pulp stem cells. Cell Biol. Int. 2018, 42, 1602-1610. [CrossRef]

27. Lei, M.; Li, K.; Li, B.; Gao, L.-N.; Chen, F.-M.; Jin, Y. Mesenchymal stem cell characteristics of dental pulp and periodontal ligament stem cells after in vivo transplantation. Biomaterials 2014, 35, 6332-6343. [CrossRef]

28. Kwon, S.Y.; Chun, S.Y.; Ha, Y.S.; Kim, D.H.; Kim, J.; Song, P.H.; Kim, H.T.; Yoo, E.S.; Kim, B.S.; Kwon, T.G. Hypoxia Enhances Cell Properties of Human Mesenchymal Stem Cells. Tissue Eng. Regen. Med. 2017, 14, 595-604. [CrossRef] 
29. Hung, S.P.; Ho, J.H.; Shih, Y.R.V.; Lo, T.; Lee, O.K. Hypoxia promotes proliferation and osteogenic differentiation potentials of human mesenchymal stem cells. J. Orthop. Res. 2012, 30, 260-266. [CrossRef]

30. Aranha, A.M.F.; Zhang, Z.; Neiva, K.G.; Costa, C.A.S.; Hebling, J.; Nör, J.E. Hypoxia enhances the angiogenic potential of human dental pulp cells. J. Endod. 2010, 36, 1633-1637. [CrossRef] [PubMed]

31. Ren, H.; Cao, Y.; Zhao, Q.; Li, J.; Zhou, C.; Liao, L.; Jia, M.; Zhao, Q.; Cai, H.; Han, Z.C.; et al. Proliferation and differentiation of bone marrow stromal cells under hypoxic conditions. Biochem. Biophys. Res. Commun. 2006, 347, 12-21. [CrossRef] [PubMed]

32. Dou, L.; Yan, Q.; Liang, P.; Zhou, P.; Zhang, Y.; Ji, P. iTRAQ-Based Proteomic Analysis Exploring the Influence of Hypoxia on the Proteome of Dental Pulp Stem Cells under 3D Culture. Proteomics 2018, 18, 1-23. [CrossRef]

33. Du, H.C.; Jiang, L.; Geng, W.X.; Li, J.; Zhang, R.; Dang, J.G.; Shu, M.G.; Li, L.W. Growth Factor-Reinforced ECM Fabricated from Chemically Hypoxic MSC Sheet with Improved in Vivo Wound Repair Activity. BioMed Res. Int. 2017, 2017. [CrossRef]

34. Wang, G.L.; Semenza, G.L. General involvement of hypoxia-inducible factor 1 in transcriptional response to hypoxia. Proc. Natl. Acad. Sci. USA 1993, 90, 4304-4308. [CrossRef] [PubMed]

35. Semenza, G.L. Defining the role of hypoxia-inducible factor 1 in cancer biology and therapeutics. Oncogene 2010, 29, 625-634. [CrossRef] [PubMed]

36. Majmundar, A.J.; Wong, W.J.; Simon, M.C. Hypoxia-Inducible Factors and the Response to Hypoxic Stress. Mol. Cell 2010, 40, 294-309. [CrossRef] [PubMed]

37. Chow, D.C.; Wenning, L.A.; Miller, W.M.; Papoutsakis, E.T. Modeling pO2 distributions in the bone marrow hematopoietic compartment. I. Krogh's model. Biophys. J. 2001, 81, 675-684. [CrossRef]

38. Gong, Q.M.; Quan, J.J.; Jiang, H.W.; Ling, J.Q. Regulation of the stromal cell-derived factor- $1 \alpha-C X C R 4$ axis in human dental pulp cells. J. Endod. 2010, 36, 1499-1503. [CrossRef]

39. Bidkhori, H.R.; Ahmadiankia, N.; Matin, M.M.; Heiranitabasi, A.; Farshchian, M.; Meshkin, H.N.; Shahriyari, M.; Dastpak, M.; Bahrami, A.R. Chemically primed bone-marrow derived mesenchymal stem cells show enhanced expression of chemokine receptors contributed to their migration capability. Iran. J. Basic Med. Sci. 2016, 19, 14-19. [CrossRef] [PubMed]

40. Heirani-Tabasi, A.; Naderi-Meshkin, H.; Matin, M.M.; Mirahmadi, M.; Shahriyari, M.; Ahmadiankia, N.; Sanjar Moussavi, N.; Bidkhori, H.R.; Raeesolmohaddeseen, M.; Bahrami, A.R. Augmented migration of mesenchymal stem cells correlates with the subsidiary CXCR4 variant. Cell Adhes. Migr. 2018, 12, 118-126. [CrossRef]

41. Kuang, R.; Zhang, Z.; Jin, X.; Hu, J.; Shi, S.; Ni, L.; Ma, P.X. Nanofibrous spongy microspheres for the delivery of hypoxia-primed human dental pulp stem cells to regenerate vascularized dental pulp. Acta Biomater. 2016, 33, 225-234. [CrossRef] [PubMed]

42. Maslowska, A.L.; Bryniarska, N.; Kubiak, A.; Kaczmarzyk, T.; Stryjewska, M.S.; Noga, S.; Boruczkowski, D.; Madeja, Z.; Surma, E.Z. Multilineage Differentiation Potential of Human Dental Pulp Stem Cells-Impact of 3D and Hypoxic Environment on Osteogenesis In Vitro. Int. J. Mol. Sci. 2020, 21, 6172. [CrossRef] [PubMed]

43. Dissanayaka, W.L.; Han, Y.; Zhang, L.; Zou, T.; Zhang, C. Bcl-2 Overexpression and Hypoxia Synergistically Enhance Angiogenic Properties of Dental Pulp Stem Cells. Int. J. Mol. Sci. 2020, 21, 6159. [CrossRef] [PubMed] 